\title{
Personality Traits of Patients with Chronic Obstructive Pulmonary Disease Who Exhibit Depression
}

J. Phys. Ther. Sci.

22: 93-99, 2010

\author{
SHOKO IWAI, OTR, MS ${ }^{1,2)}$, HideAKI SENJYU, RPT, $\mathrm{PhD}^{1)}$, RUMI KANEDA, RPT, MS ${ }^{1)}$, \\ ASUKA IGUCHI, RPT, MS ${ }^{1)}$, YoshiKa HAYASHI, MS ${ }^{3)}$, HIROKI OZAWA, MD, PhD'), \\ SUMIHISA HONDA, $\mathrm{PhD}^{4}$, MisAKo HigashiJima, OTR, $\mathrm{PhD}^{1)}$ \\ ${ }^{1)}$ Courses of Health Sciences, Nagasaki University Graduate School of Biomedical Sciences: \\ 1-7-1 Sakamoto, Nagasaki-city, Nagasaki 852-8520, Japan. \\ TEL: +81 95-819-7963,FAX: +8195-819-7963,E-mail: shoko1117@kaw.bbiq.jp \\ ${ }^{2)}$ Department of Rehabilitation, Tagami Hospital \\ ${ }^{3)}$ Department of Neuropsychiatry, Unit of Translational Medicine, Nagasaki University \\ Graduate School of Biomedical Science \\ ${ }^{4)}$ Department of Public Health, Nagasaki University Graduate School of Biomedical Science
}

\begin{abstract}
Purpose] The objective of this study was to examine the differences in personality traits based on the presence of depression in chronic obstructive pulmonary disease (COPD) patients. [Subjects and Methods] The current study involved 39 subjects with COPD. Personality traits of subjects were compared with the presence of depression and effectors of depression, including personality traits, were reviewed. [Results] Fourteen subjects (35.9\% of the total) were classified as having depression (Center for Epidemiologic Studies Depression Scale (CES-D) $\geq 16$ ). Subjects who exhibited depression also displayed differences in items of the Yatabe-Guilford personality inventory and demonstrated high values for all St. George's Hospital Respiratory Questionnaire (SGRQ) items. Additionally these personality traits and SGRQ items were partially correlated with CES-D score. Effectors for CES-D were "Nervousness" "Sense of cooperation", and "Symptoms" of SGRQ. [Conclusion] Subjects who exhibited depression displayed traits such as a sense of inferiority, nervousness, lack of cooperation, inactivity, thinking introversion, excessive punctuality and unsociability. Therefore, in COPD patients, consideration of personality traits can be linked to early detection and appropriate treatment of depression via methods such as group cognitive behavioral therapy in respiratory rehabilitation.
\end{abstract}

Key words: Chronic obstructive pulmonary disease (COPD), Depression, Personality trait

(This article was submitted Aug. 24, 2009, and was accepted Nov. 5, 2009)

\section{INTRODUCTION}

Chronic obstructive pulmonary disease (COPD) is a lifestyle-related disease that is associated with long-term smoking, and the WHO predicts that COPD will be the third leading cause of death in the world by $2020^{1)}$. In Japan, the number of COPD patients has displayed a rapid increase in association with an aging society as demonstrated by reports ${ }^{2)}$ stating that the number of COPD patients in 2001 was approximately 5.3 million, with a prevalence of $8.5 \%$ in adults aged 40 years and older.

Depression is often co-morbid with COPD. The frequency of depression in COPD patients is reported as $7 \%$ to $58.3 \%$ overseas $^{3)}$ and $23 \%$ in 
Japan $^{4)}$ employing evaluation methods such as the Center for Epidemiologic Studies Depression Scale $(\mathrm{CES}-\mathrm{D})^{5)}$ and the Hospital Anxiety and Depression Scale(HADS $)^{6}$. Depression in COPD tends to occur approximately twice as compared to other diseases ${ }^{7)}$. In turn, this situation impacts the healthrelated quality of life (HRQOL) ${ }^{8)}$ in terms of the St. George's Hospital Respiratory Questionnaire $\left(\right.$ SGRQ) ${ }^{9)}$, mortality rate ${ }^{10)}$, etc. Moreover, in the Global Initiative for Chronic Obstructive Lung Disease (GOLD) 2006 ${ }^{11)}$, the importance of the mental healthcare of COPD patients was noted. In Japan, however, no reports pertaining to research focusing on the mental health of COPD patients appears in the literature. Furthermore, no appropriate care guidelines or strategies exist with respect to the current environment.

Genetic factors, psychosocial factors, including elements such as life events, personality traits, cognitive style and social support, and brain function/organic factors are related to the pathology of depression. Past reports confirm a causal relationship between a high number of negative life events and depression ${ }^{12}$. However, given that the percentage at which such events affect depression is 5 to $20 \%{ }^{13)}$, the involvement of internal factors such as personality traits is a focal point. Personality traits relating to depression and depression symptoms include a melancholic type ${ }^{14)}$, immodithymia ${ }^{15)}$ and anankastic/avoidant personalities in Diagnostic and Statistical Manual of Mental Disorders IV(DSM-IV) ${ }^{16)}$. In instances of senile depression, seriousness and conscientiousness, thoroughness and introversion, etc., have been noted ${ }^{17)}$. It has been reported that factors affecting depression accompanying COPD include female gender ${ }^{18)}$, a more severe case of COPD $^{19)}$, living alone ${ }^{19)}$ and high income and education level ${ }^{7)}$. However, no studies appear in the literature regarding personality traits.

The objective of this study was to examine the differences in personality traits based on the presence of depression in COPD patients, to review personality traits as effectors of depression as well as to establish a link to clinical early clinical detection of depression in COPD patients, appropriate treatment and how to relate to such patients.

\section{SUBJECTS AND METHODS}

Subjects consisted of 39 COPD patients characterized by stable pathological conditions who did not exhibit dementia.

CES-D ${ }^{5)}$, which is often used in the field of psychiatry, was applied to evaluate depression. Depression is typically judged as a score exceeding 16 points $^{5}$.

In terms of personality traits, the Yatabe-Guilford personality test (YG personality test) ${ }^{20}$ ) was employed.

HRQOL unique to respiratory disease was also evaluated with the SGRQ ${ }^{9}$. Vital capacity (VC), \% vital capacity $(\% \mathrm{VC})$, forced expiratory volume in one second $\left(\mathrm{FEV}_{1.0}\right), \%$ forced expiratory volume in one second $\left(\% \mathrm{FEV}_{1.0}\right)$ and forced expiratory volume in one second as percent of $\mathrm{FVC}\left(\mathrm{FEV}_{1.0} \%\right)$ were based on a respiratory function test. In addition, interviews were conducted regarding general information, including BMI, age, family constitution, smoking history, oxygen therapy status and Medical Resarch Council dyspnea scale (MRC scale).

All analyses were conducted using SPSS 16.0J for Windows. The t-test was utilized to compare measurement items with presence of depression. In addition, the $\chi^{2}$ test with used to test the relevance between presence of depression and personality types of the YG personality test as well as other factors and Pearson's product-moment correlation coefficient for relevance between CES-D scores and the various evaluation items were employed. The influence of each evaluation item on CES-D scores was assessed with multiple regression analysis with CES-D scores serving as the dependent variable and base factor scores of the YG personality test, SGRQ subscores, respiratory function test value and age as the independent variables.

\section{RESULTS}

Characteristics of the subjects are presented in Table 1. Subjects consisted of 39 males, 16 inpatients and 23 out-patients. All subjects had a history of smoking. Fourteen individuals, or 35.9\% of the total, were judged as having depression.

A comparison (Table 2) between the group of subjects with depression (CES-D $\geq 16$ ) (Group A) and the group of subjects without depression (Group B) revealed no significant differences in age, body 
Table 1. Characteristics of the subjects $(n=39)$

\begin{tabular}{lc}
\hline & Mean \pm SD \\
\hline Age (year) & $73 \pm 8$ \\
Height $(\mathrm{cm})$ & $162 \pm 4$ \\
Weight $(\mathrm{kg})$ & $56 \pm 9$ \\
BMI $\left(\mathrm{kg} / \mathrm{m}^{2}\right)$ & $21 \pm 3$ \\
VC $(\mathrm{L})$ & $3.0 \pm 0.7$ \\
$\%$ VV $(\%)$ & $92.8 \pm 21.1$ \\
$\mathrm{FEV}_{1.0}(\mathrm{~L})$ & $1.5 \pm 0.7$ \\
$\% \mathrm{FEV}_{1.0}(\%)$ & $55.8 \pm 20.0$ \\
FEV $_{1.0} \%(\%)$ & $51.0 \pm 15.2$ \\
\hline
\end{tabular}

composition and each of the measurement values for the pulmonary function test.

For the YG personality test, "Depression", "Cyclic tendency", "Inferiority feeling", "Nervousness", "Objectivity" and "Sense of cooperation" were significantly higher in Group A than in Group B ("Sense of cooperation": $p<0.05$, others: $p<0.01$ ), whereas "General activity" and "Ascendance(Leadership)" were significantly lower $(\mathrm{p}<0.05)$. No significant differences were detected in "Agreeableness", "Rhathymia", "Thinking extraversion" and "Sociability". For SGRQ, all subscores were significantly higher in Group A than in Group B $(\mathrm{p}<0.01)$.

Table 3 demonstrates the association between the presence of depression and the YG personality test type. In Group A, four subjects were classified as Type B (Black List Type) and six were classified as Type E (Eccentric Type). In Group B, 16 subjects were classified as Type D (Director Type), which is a strikingly high number in comparison to the rest of the types. This result is indicative of a meaningful relationship between the presence of depression and the YG personality test types $(\mathrm{p}<0.001)$.

Table 4 displays the relevance between the presence of depression and other factors. The degree of severity was reviewed by classification of the subjects into two categories based on the severity classifications of GOLD 2006 ${ }^{11)}$ —a mild group, comprised of cases exhibiting mild to moderate severity $\left(\% \mathrm{FEV}_{1.0} \geq 50 \%\right)$, and a severe

Table 2. Comparison of evaluation items depending on presence of depression

\begin{tabular}{|c|c|c|}
\hline & $\begin{array}{l}\text { Group with depression } \\
\qquad(\mathrm{n}=14)\end{array}$ & $\begin{array}{l}\text { Group without depression } \\
\qquad(\mathrm{n}=25)\end{array}$ \\
\hline Age (year) & $74 \pm 7$ & $73 \pm 8$ \\
\hline BMI $\left(\mathrm{kg} / \mathrm{m}^{2}\right)$ & $21 \pm 4$ & $22 \pm 3$ \\
\hline $\mathrm{VC}(\mathrm{L})$ & $2.8 \pm 0.6$ & $3.1 \pm 0.8$ \\
\hline$\% \mathrm{VC}(\%)$ & $87.6 \pm 17.3$ & $95.7 \pm 22.8$ \\
\hline $\mathrm{FEV}_{1.0}(\mathrm{~L})$ & $1.2 \pm 0.5$ & $1.6 \pm 0.7$ \\
\hline$\% \mathrm{FEV}_{1.0}(\%)$ & $47.8 \pm 17.9$ & $60.8 \pm 19.6$ \\
\hline MRC scale & $3.1 \pm 1.1$ & $2.4 \pm 1.4$ \\
\hline CES-D (points) & $22.6 \pm 9.0^{* *}$ & $9.4 \pm 3.0^{* *}$ \\
\hline \multicolumn{3}{|l|}{ SGRQ } \\
\hline Total & $59 \pm 21$ & $34 \pm 19 * *$ \\
\hline Symptoms & $59 \pm 21$ & $41 \pm 18 * *$ \\
\hline Activity & $74 \pm 27$ & $46 \pm 32 * *$ \\
\hline Impacts & $51 \pm 21$ & $25 \pm 16^{* *}$ \\
\hline \multicolumn{3}{|l|}{ Basic factors for $Y G$} \\
\hline Depression & $13 \pm 4$ & $4 \pm 4^{* *}$ \\
\hline Cyclic tendency & $13 \pm 4$ & $6 \pm 4 * *$ \\
\hline Inferiority feeling & $10 \pm 5$ & $5 \pm 4 * *$ \\
\hline Nervousness & $13 \pm 5$ & $6 \pm 4 * *$ \\
\hline Objectivity & $12 \pm 4$ & $6 \pm 3 * *$ \\
\hline Sense of cooperation & $11 \pm 5$ & $7 \pm 5^{*}$ \\
\hline Agreeableness & $12 \pm 3$ & $13 \pm 5$ \\
\hline General activity & $10 \pm 4$ & $14 \pm 5^{*}$ \\
\hline Rhathymia & $9 \pm 4$ & $11 \pm 5$ \\
\hline Thinking extraversion & $9 \pm 5$ & $11 \pm 4$ \\
\hline Ascendance (Leadership) & $8 \pm 4$ & $11 \pm 5^{*}$ \\
\hline Sociability & $10 \pm 3$ & $13 \pm 5$ \\
\hline$* \mathrm{p}<0.05, * * \mathrm{p}<0.01$ & & Mean \pm SD \\
\hline
\end{tabular}


Table 3. Relevance between presence of depression and TG types

\begin{tabular}{|c|c|c|c|}
\hline & $\begin{array}{c}\text { Group with depression } \\
\qquad(\mathrm{n}=14)\end{array}$ & \multicolumn{2}{|c|}{$\begin{array}{l}\text { Group without depression } \\
\qquad(\mathrm{n}=25)\end{array}$} \\
\hline Type A & $3(37.5 \%)$ & 5 & \\
\hline B & $4(100 \%)$ & 0 & \\
\hline $\mathrm{C}$ & $1(20.0 \%)$ & 4 & $\mathrm{p}<0.001$ \\
\hline D & $0(0 \%)$ & 16 & \\
\hline E & $6(100 \%)$ & 0 & \\
\hline
\end{tabular}

Table 4. Relevance between presence of depression and each evaluation item

\begin{tabular}{lccc}
\hline & $\begin{array}{c}\text { Group with depression } \\
(\mathrm{n}=14)\end{array}$ & $\begin{array}{c}\text { Group without depression } \\
(\mathrm{n}=25)\end{array}$ & \\
\hline $\begin{array}{l}\text { GOLD severity classification } \\
\text { Mild/moderate }\end{array}$ & $4(18.2 \%)$ & 18 & \\
$\quad$ Severe/very severe & $10(58.8 \%)$ & 7 & \\
Environment & & 7 & \\
$\quad$ Hospitalized & $9(56.3 \%)$ & 18 & \\
At home & $5(21.7 \%)$ & 3 & \\
Family constitution & $1(25.0 \%)$ & 22 & \\
$\quad$ Living alone & $13(37.1 \%)$ & $\mathrm{p}=0.009$ \\
2 or more people & & & \\
\hline
\end{tabular}

Table 5. Correlation coefficients for depression and various evaluation results

\begin{tabular}{|c|c|c|c|c|c|c|}
\hline & & & & & & \\
\hline & CES-D & $70 \Gamma \mathrm{L} \mathrm{v}_{1.0}$ & Total & Symptoms & Activity & Impacts \\
\hline CES-D & & & & & & \\
\hline$\% \mathrm{FEV}_{1.0}$ & -0.188 & & & & & \\
\hline SGRQ & & & & & & \\
\hline Total & $0.555 * *$ & $-0.468 * *$ & & & & \\
\hline Symptoms & $0.469 * *$ & $-0.434^{*}$ & $0.778 * *$ & & & \\
\hline Activity & $0.408 *$ & $-0.485 * *$ & $0.924 * *$ & $0.597 * *$ & & \\
\hline Impacts & $0.613 * *$ & $-0.377 *$ & $0.958 * *$ & $0.732 * *$ & $0.796 * *$ & \\
\hline Basic factors for $Y G$ & & & & & & \\
\hline Depression & $0.566^{* *}$ & -0.082 & $0.425 * *$ & 0.233 & $0.342 *$ & $0.483 * *$ \\
\hline Cyclic tendency & $0.547 * *$ & -0.018 & $0.411 *$ & $0.339 *$ & 0.321 & $0.441 * *$ \\
\hline Inferiority feeling & $0.563 * *$ & 0.014 & 0.178 & 0.116 & 0.093 & 0.240 \\
\hline Nervousness & $0.629 * *$ & -0.051 & $0.443 * *$ & 0.250 & $0.353^{*}$ & $0.504 * *$ \\
\hline Objectivity & $0.553 * *$ & -0.018 & $0.359 *$ & 0.296 & 0.255 & $0.406^{*}$ \\
\hline Sense of cooperation & $0.415 * *$ & 0.133 & -0.043 & -0.136 & -0.108 & 0.051 \\
\hline Agreeableness & -0.064 & 0.233 & -0.187 & -0.100 & -0.236 & -0.138 \\
\hline General activity & -0.247 & $0.499 * *$ & $-0.442 * *$ & $-0.452 * *$ & $-0.409 *$ & $-0.389 *$ \\
\hline Rhathymia & -0.070 & $0.340 *$ & -0.232 & -0.126 & -0.203 & -0.247 \\
\hline Thinking extraversion & -0.203 & 0.045 & -0.254 & -0.082 & -0.223 & -0.289 \\
\hline Ascendance (Leadership) & -0.213 & 0.105 & -0.260 & -0.050 & -0.279 & -0.262 \\
\hline Sociability & -0.278 & 0.063 & $-0.369 *$ & -0.213 & -0.305 & $-0.408^{*}$ \\
\hline Age & -0.141 & $-0.341 * *$ & $-0.343 *$ & 0.171 & $0.402 *$ & 0.284 \\
\hline
\end{tabular}


Table 6. Effectors for CES-D

\begin{tabular}{lccc}
\hline $\begin{array}{c}\text { Dependent } \\
\text { variable }\end{array}$ & $\begin{array}{c}\text { Independent } \\
\text { variable }\end{array}$ & $\begin{array}{c}\text { Standardization } \\
\text { coefficient }\end{array}$ & $\begin{array}{c}\text { Level of } \\
\text { significance }\end{array}$ \\
\hline CES-D & YG personality test & & \\
& $\quad \begin{array}{c}\text { Nervousness } \\
\text { Sense of cooperation }\end{array}$ & 0.541 & 0.001 \\
& SGRQ & 0.388 & 0.006 \\
& Symptoms & 0.498 & 0.000 \\
\hline
\end{tabular}

group comprised of severe to very severe cases $\left(\% \mathrm{FEV}_{1.0}<50 \%\right)$. As a result, significant relevance between depression and degree of severity was apparent $(\mathrm{p}=0.009)$; furthermore, relevance was higher in severe and very severe cases $(58.8 \%)$. In terms of the environment, significant relevance was observed $(\mathrm{p}=0.027)$, and higher relevance was evident in a hospitalized environment $(56.3 \%)$. However, relevance was not indicated for family constitution (living alone/2 or more people) $(\mathrm{p}=0.545)$.

In terms of the relationship between CES-D scores and various evaluation items (Table 5), significant correlation was evident between CES-D and all SGRQ items as well as with "Depression", "Cyclic tendency", "Inferiority feeling", "Nervousness", "Lack of objection" and "Lack of cooperation" from the YG personality test. No correlation was observed between CES-D and age or $\% \mathrm{FEV}_{1.0}$, which indicates the degree of severity based on respiratory function. $\% \mathrm{FEV}_{1.0}$ displayed correlation with all SGRQ items.

"Nervousness" $(\beta=0.541)$, "Sense of cooperation" $(\beta=0.388)$ from the YG personality test and "Symptoms" of SGRQ $(\beta=0.498)$ were the only independent variables affecting CES-D scores (Table 6).

\section{DISCUSSION}

Frequency of depression was $35.9 \%$ among subjects in this investigation. In addition, inpatients displayed a higher frequency of depression than out-patients, which was identical to the findings of Andenaes $\mathrm{R}^{21)}$. Frequency of depression among COPD patients was reported as $23 \%$ by van Manen JG et al. ${ }^{19)}$ employing CES-D, and in Japan, $21 \%$ by Kagaya et al.4) employing HADS. Although these percentages are based on out-patient subjects, in-patients were present in the current study, which may account for the higher percentage of subjects as judged as having depression.

With regard to differences in personality traits, based on results of the YG personality test, COPD patients exhibiting depression were characterized as having the following traits: lethargy, despondency, a rise and fall in emotions, sense of inferiority, nervousness, subjectivity, stubbornness, lack of cooperation, a tendency to be guarded, distrustful and cautious of others, inactivity, introversion in terms of thinking (thinks deeply about details since he/she tries to solve problems in his/her own mind using internal methods), excessively punctuality, submissive, unsociable, conscientious, shy and withdrawn, and low self-esteem. In terms of premorbid traits for depression, a methodical, conscientious melancholic type personality has been reported by Tellnbach ${ }^{14)}$; furthermore, immodithymia, indicative of emotional continuance, has been documented by Shimoda ${ }^{15)}$. Additionally, an anankastic personality displaying a tendency towards stubbornness and lack of adaptability as well as an avoidant personality displaying a sense of inferiority, low self-esteem, rejection by others, sensitivity to criticism, avoidance of interactions with other people due to fear of failure, and shyness have been described by Jeffrey et al. ${ }^{16)}$. In terms of personality traits of senile depression, Pitt et al. ${ }^{17)}$ reported seriousness combined with conscientiousness, thoroughness, introversion, etc. These traits are similar to the personality traits indicated in this study. Conversely, individuals who did not exhibit depression demonstrated tendencies toward being very optimistic, calm, objective, dynamic, cooperative, active, extroverted in terms of thinking (does not concern himself/herself with details, since he/she takes interest in other things without solving problems using methods inside his/her mind), ascendant, self-confident and sociable. 
According to a report ${ }^{20}$ examining $Y G$ personality test types, the majority of neurotics were Type E, followed by Type B. Moreover, Type $\mathrm{D}$ was most prevalent in healthy subjects. These findings are similar to the present findings for COPD patients. Type B which represents emotional instability and extroversion, and Type E which represents emotional instability and introversion, both demonstrate emotional instability, wariness of surroundings, an autistic attitude, problems in interpersonal relationships and social maladjustment. In contrast, Type $\mathrm{D}$, a leader type marked by emotional stability and active behavior, was found to be strikingly high in persons not exhibiting depression, who display social adjustability and no problems in interpersonal relationships.

Based on the aforementioned reports, excessive anxiety regarding unpredictable respiratory difficulties and exacerbation of symptoms as well as pessimism with respect to handling changes in symptoms and appearance are linked to depression in COPD patients. Furthermore, the inability to flexibly change these kinds of thoughts or feelings, and extreme cautiousness with respect to others, results in an inability to open their's inner thoughts, which may exert a further synergistic effect on depression. In contrast, based on the types of personality traits demonstrated in persons who do not exhibit depression, the ability to calmly and objectively process external factors and to direct interest toward other matters enables these individuals to avoid depression.

In addition to the relationship between depression and smoking dependency ${ }^{22}$, which is a cause of COPD, several reports appear in the literature regarding the relationship ${ }^{23}$ ) between dependency on smoking and personality traits displayed by COPD patients who exhibited depression in this study, such as emotional instability and nervousness. This finding suggests that in COPD patients, these personality traits exert an impact and are linked to smoking dependency as well as to COPD, which increases the susceptibility of the patients to depression.

Depression corresponded to lower HRQOL in COPD patients. Jeffrey et al. ${ }^{16)}$ presented similar results for HRQOL of COPD patients exhibiting depression. Furthermore relationships between HRQOL and personality traits as well as $\% \mathrm{FEV}_{1.0}$ were demonstrated in the present study. Therefore it appears that lethargy, the rise and fall of emotions, nervousness and pessimism for symptoms, and decrease of activity lead to degradation of HRQOL.

Severity was indicated as a factor related to the presence of depression. van Manen JG et al. ${ }^{19)}$ reported increased risk of depression in patients with severe COPD, which is consistent with the results of the present study. However, the personality traits and HRQOL are included as effectors of CES-D scores; the measurement values for the pulmonary function test was not included. Accordingly, these data suggest that personality traits and a decrease in HRQOL affect depression more greatly than the severity of COPD based on respiratory function.

Based on the aforementioned findings, in terms of the high frequency of depression in COPD patients and the magnitude of its impact, it is possible to evaluate psychological symptoms including depression in a standard manner. Furthermore, relevant factors, consisting not only of the degree of severity based on pulmonary function, but also of personality traits, interpersonal relationships, social adjustability, HRQOL, etc., may be considered so as to enable early detection of depression. In addition, accounting for the differences in personality traits according to the presence of depression can also be linked to the conduction of appropriate treatment such as group cognitive behavioral therapy for depression in respiratory rehabilitation through respiratory rehabilitation classes and patients' associations and by providing patient education regarding the disease and guidance with respect to smoking cessation in a manner where attention is given to the concerns of patients, so that patients do not harbor unrealistic expectations and can avoid failure.

Limitations of this study include the small sample size and the longitudinal design. In the future, investigations involving larger subject numbers and reviews of personality traits that include females and non-smokers are necessary. Furthermore, cross-sectional research is required to assess whether these personality traits are direct factors related to the causes of depression.

\section{ACKNOWLEDGMENTS}

The authors would like to thank the patients and the staff members at various facilities who participated in this study. 


\section{REFERENCES}

1) Murray $\mathrm{CJ}$, Lopez $\mathrm{AD}$ : Alternative projections of mortality and disability by cause 1990-2020: Global Burden of Disease Study. Lancet, 1997, 349(9064): 1498-1504.

2) Fukuchi $Y$, Nishimura M, Ichinose $M$, et al.: COPD in Japan: the Nippon COPD epidemiology study. Respirology, 2004, 9: 458-465.

3) Hynninen KM, Breitve $\mathrm{MH}$, Wiborg $\mathrm{AB}$, et al.: Psychological characteristics of patients with chronic obstructive pulmonary disease: a review. J Psychosom Res, 2005, 59: 429-443.

4) Kagaya $H$, Takahashi H, Sugawara K, et al.: Predicting factor of depression and anxiety in patients with chronic obstructive pulmonary disease. General Rehabilitation, 2005, 33: 871-874.

5) Radloff LS: The CES-D Scale: a self-report depression scale for research in the general population. Appl Psychol Meas, 1997, 1: 385-401.

6) Zigmond AS, Snaith RP: The hospital anxiety and depression scale. Acta Psychiatr Scand, 1983, 67: 361370.

7) Lin $M$, Chen $Y$, McDowell I: Increased risk of depression in COPD patients with higher education and income. Chron Respir Dis, 2005, 2: 13-19.

8) Kerstin K, Wolfgang S, Winfried R: Mental disorders and quality of life in COPD patients and their spouses. Int J Chron Obstruct Pulmon Dis, 2008, 3: 727-736.

9) Jones PW, Quirk FH, Baveystock CM, et al.: A selfcomplete measure of health status for chronic airflow limitation. The St. George's Respiratory Questionnaire. Am Rev Respir Dis, 1992, 145: 13211327.

10) Fan VS, Ramsey SD, Giardino ND, et al.: Sex, depression, and risk of hospitalization and mortality in chronic obstructive pulmonary disease. Arch Intern Med, 2007, 167: 2345-2353.

11) Global Intiative for Chronic Obstructive Lung Disease. Global strategy for the diagnosis, management, and prevention of chronic obstructive pulmonary disease, updated 2008. http//www.goldcopd.com/ (Accessed
Apr. 13, 2009)

12) Lewinsohn PM, Hoberman HM, Rosenbaum M: A prospective study of risk factors for unipolar depression. J Abnorm Psychol, 1988, 97: 251-264.

13) Robinson NS, Garber J, Hilsman R: Cognitions and stress: direct and moderating effects on depressive versus externalizing symptoms during the junior high school transition. J Abnorm Psychol, 1995, 104: 453463.

14) Tellenbach H: Melancholie. Berlin: Springer, 1976(in German).

15) Shimoda M: Premorbid character of manic depression illness. Psychiatria et Neurologia Japonica, 1941, 43: 45-101(in Japanese).

16) Jeffrey GJ, Patricia C, Stephanie K, et al.: Personality disorder traits associated with risk for unipolar depression during middle adulthood. Psychiatry Res, 2005, 136: 113-121.

17) Pitt B: Psychogeriatricus. Edinburgh London: Churechill Livingstone, 1974.

18) Laurin C, Lavoie KL, Bacon SL, et al.: Sex differences in the prevalence of psychiatric disorders and psychological distress in patients with COPD. Chest, 2007, 132: 148-155.

19) van Manen JG, Bindels PJ, Dekker FW, et al.: Risk of depression in patients with chronic obstructive pulmonary disease and its determinants. Thorax, 2002, 57: 412-416.

20) Tsujioka $M$ : Yatabe-Guilford personality inventory. Psychology, 1951, 1: 70-100(in Japanese).

21) Andenaes R, Kalfoss MH: Psychological distress in hospitalized patients with chronic obstructive pulmonary disease. Eur J Epidemiol, 2004, 19: 851856.

22) Breslau N, Peterson EL, Schultz LR, et al:: Major depression and stages of smoking. A longitudinal investigation. Arch Gen Psychiatry, 1998, 55: 161166.

23) Eysenck HJ, Eaves LJ, Kasriel J: The Causes and Effects of Smoking. Hampshire: Gomer Publishing Company, 1988. 